\title{
Large Angioleiomyoma on the Face
}

\author{
${ }^{1}$ Vikram Kulkarni, ${ }^{2}$ Vidisha Athanikar, ${ }^{3}$ Trupti Katti \\ ${ }^{1}$ Associate Professor, Department of ENT, Navodaya Medical College Hospital and Research Center, Raichur, Karnataka, India \\ ${ }^{2}$ Professor, Department of Pathology, Navodaya Medical College Hospital and Research Center, Raichur, Karnataka, India \\ ${ }^{3}$ Assistant Professor, Department of Pathology, Navodaya Medical College Hospital and Research Center, Raichur, Karnataka, India
}

Correspondence: Vikram Kulkarni, Associate Professor, Department of ENT, Navodaya Medical College Hospital and Research Center, Mantralayam Road, Raichur, Karnataka-584103, India, Phone: 09845182663, e-mail: drvikubaba@hotmail.com

\begin{abstract}
Objective: To report a rare case of angioleiomyoma with regard to size, type (variant) and location.

Case report: 45 years old male presented with painless swelling on the right side of the face since 2 years. On examination, the swelling was $4 \mathrm{~cm} \times 3 \mathrm{~cm}$ in size, firm in consistency with well-defined margins. It was not adhering to overlying skin and underlying structures. The swelling was excised and sent for histopathological diagnosis. It was reported as solid variant of angioleiomyoma based on microscopic features.

Conclusion: According to the world literature, large angioleiomyoma on face is rare or not reported yet (usually less than $2 \mathrm{~cm}$ ) and location (usually externar ear, tip of nose, lip). This case is presented for its uniqueness in size -large $(4 \mathrm{~cm} \times 3 \mathrm{~cm})$; painlessness; variant; and location.
\end{abstract}

Keywords: Angioleiomyoma, face.

\section{INTRODUCTION}

Angioleiomyomas are benign tumors containing mature smooth muscle cells interspersed with blood vessels and occur as solitary subcutaneous nodules. Causative factor of the origin of these tumors is unknown. Histologically they are divided into three variants as solid, venous and cavernous. ${ }^{1,2}$ Most of the tumors occurring in the extremities are painful and occur in third decade onwards. ${ }^{1,2}$ It is rare to find such tumor in the head and neck region with or without pain. One such angioleiomyoma is reported here.

\section{CASE HISTORY}

A 42 years old male patient came to ENT opd and presented with painless swelling over the right side of the face since 2 years. On examination, an oval swelling was present over the right side of face below medial one third of the orbit measuring $4 \mathrm{~cm} \times 3 \mathrm{~cm}$ in size (Fig. 1). It was subcutaneous in plane and free from the underlying bone with wellcircumscribed margins. It was firm in consistency and nontender. The lesion was well-encapsulated, excised (Fig. 2) and sent for histopathological examination. On cut section (Fig. 3), the swelling was pinkish white and solid with

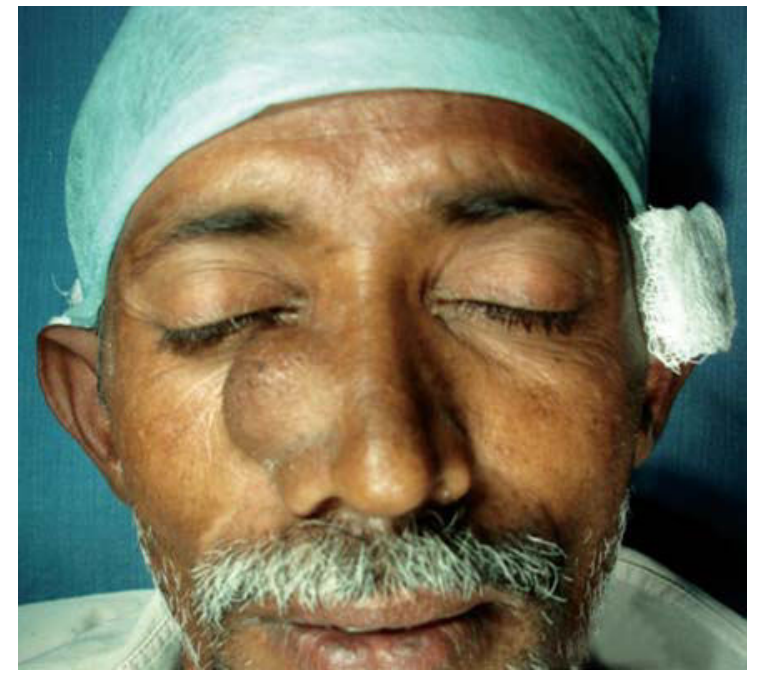

Fig. 1: Oval swelling on the face

multiple bleeding spots. Routine H\&E stained histopathological sections studied revealed a well-circumscribed tumor mass enclosing spindle shaped tumor cells arranged in whorls, bundles and interlacing fascicles (Fig. 4). These cells showed moderate amount of pale eosinophilic cytoplasm and plump spindle shaped nucleus. Interspersed are fair number of slit like and dilated vascular lumina lined by single layer of endothelial cells, some of which enclosing 


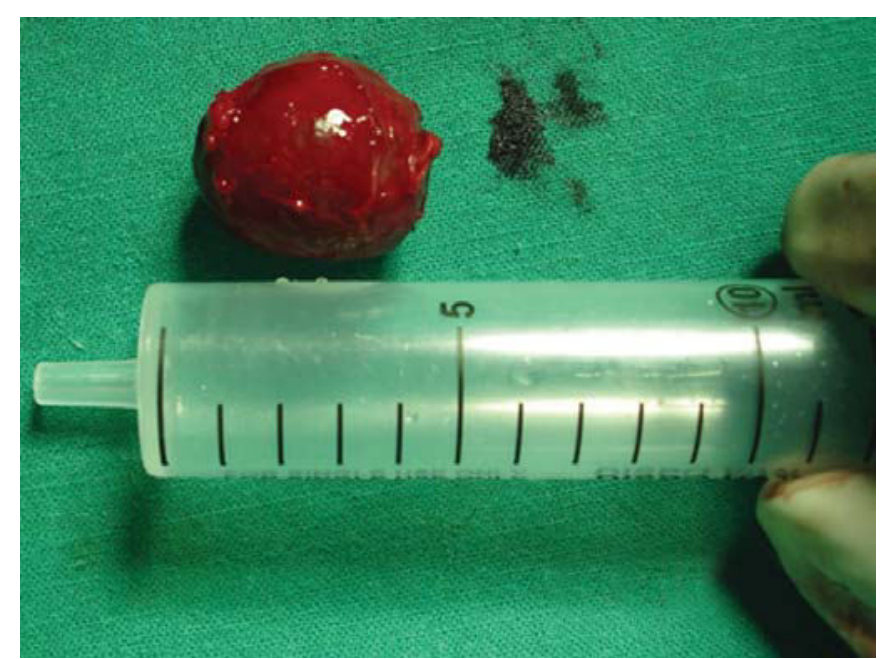

Fig. 2: Excised tumor

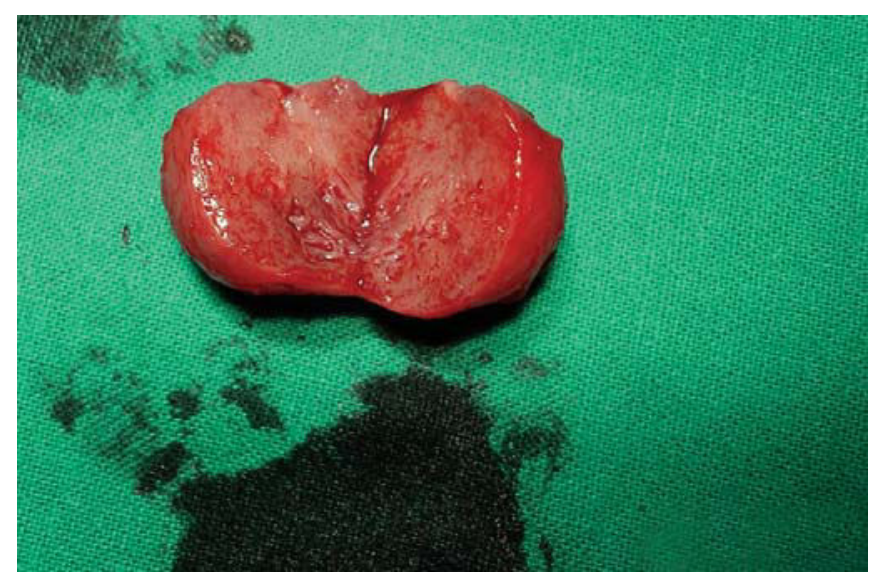

Fig. 3: Macroscopic appearance on cut section

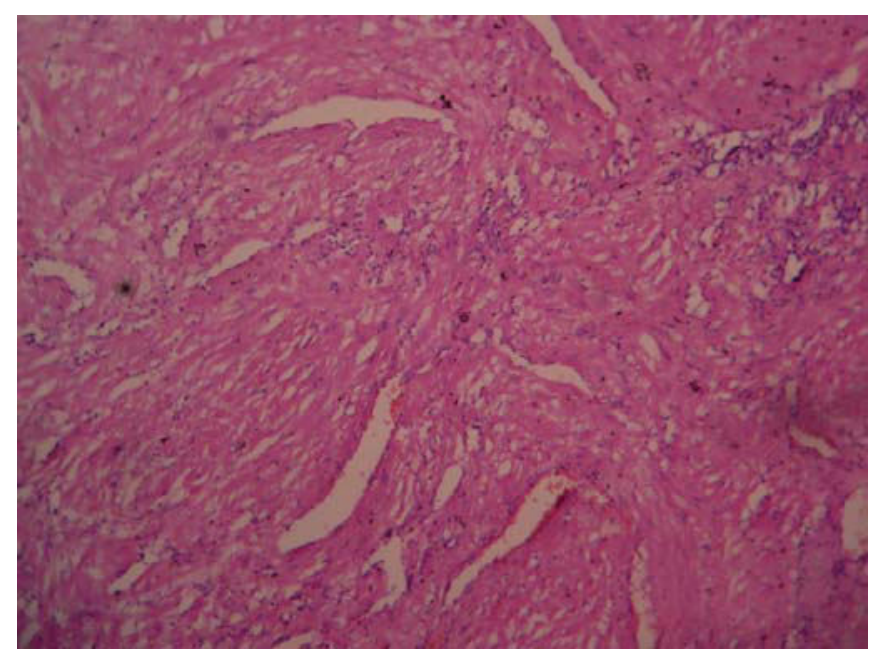

Fig. 4: H\&E stained section specimen on microscopic examination magnification $40 x$
RBCs within the lumen. The tumor also shows focal islands of mature fat cells. There is no evidence of nuclear atypia, mitosis or necrosis in the tumor tissue. The diagnosis of solid variant of angioleiomyoma was given. The patient did not have hematoma postoperatively and is on regular follow up for signs of recurrence.

\section{DISCUSSION}

There are several reports of the angioleiomyomas from various parts of the body. In these reports the predominant site of occurrence was lower extremities. ${ }^{1,2}$ There are very few reports of these tumors occurring in the head and neck. In a recent study, 21 cases of angioleiomyomas were reported by Wang CP et al over a period of 13 years. Of these, 5 were from auricle, 3 on the external skin of the nose, 3 in the nasal cavity and 3 over the lip. Other reported sites in head and neck include external auditory canal, ${ }^{3}$ lacrimal region ${ }^{4}$ and 3 in the deep neck spaces. ${ }^{5}$ The case reported here is situated on the right side of the face below the medial one third of the orbit which is unique.

The mechanism of development of these tumors is unknown but has been postulated to be hamartomatous, hormonal, mechanical. ${ }^{2,3}$ Most of the angioleiomyomas are reported to be small and less than $2 \mathrm{~cm}^{2}$ except in two which occurred in deep neck spaces. ${ }^{5}$ Reported case here measured $4 \times 3 \mathrm{~cm}$ in size.

Most of the angioleiomyoma reported from head and neck region ${ }^{1,2}$ were of either cavernous or venous type except that reported by Wang CP et al in which majority were solid variants. Head and neck angioleiomyomas are mostly painless and solid variants ${ }^{5}$ with one exception. ${ }^{6}$ The mechanism for the pain is thought to be contraction of the vessels giving rise to local ischemia. ${ }^{2}$

The diagnosis of these tumors are evident only on excision biopsy and histopathological examination as there are few reports of diagnostic study by Fnac or ultrasonography. Though they are vascular, the bleeding from these lesions is insignificant. This is most probably because the vessels feeding them are very small. ${ }^{5}$ In our case we encountered two minor veins over the lesion and were effectively cauterized without much bleeding. Recurrence of these tumors is rare if complete excision is done. 


\section{SUMMARY}

Angioleiomyomas are truly rare to find on the face. One such case solid painless tumor over the face is reported which is largest amongst reported cases. Further, angioleiomyomas should be one of the differential diagnosis of the facial subcutaneous tumors.

\section{REFERENCES}

1. Matsuyama A, Hisaoka M, Hashimoto H. Angioleiomyoma: A clinicopathological and immunohistochemical reappraisal with special reference to the correlation with myopericytoma. Human pathology 2007;38:645-51.
2. Huchisuga T, Hashimoto H, Enjoji M. Angioleiomyoma: A clinicopathological Reappraisal of 562 cases. Cancer 1984;54:126-30.

3. Piccotti PM, Cantore I, La Greca C, Di Nardo W, Scaarano E. Angioleiomyoma of the external auditory canal. American journal of otolaryngology and head and neck surgery 2007;28:235-37.

4. Korn BS, Glasgow BJ, O Kikkawa D. Epiphora as a presenting sign of Angioleiomyoma of the lacrimal sac. Ophthal Plastic Reconstr Sur 2007;23(6):490-92.

5. Wang CP, Chang YL, Sheen TS. Vascular leiomyoma of the head and neck. Laryngoscope 2004;114:661-65.

6. Carpenter PM, Sundine MJ, Kong AP, Wirth GA. Auricular angioleiomyoma: A case report and review of the literature. Ear, Nose and Throat journal May 2007;281-83. 